\title{
Knowledge and Practice of Malaria Control Measures among Women Attending Antenatal Clinics in Abakaliki, Nigeria
}

\author{
Azuogu $\mathrm{VC}^{1} *$, Ndie $\mathrm{CE}^{2}$, Onah $\mathrm{CK}^{3}, \mathrm{Akpa} \mathrm{CO}^{3}$, Eze $\mathrm{NC}^{4}, \mathrm{Azuogu} \mathrm{BN}^{3}$ \\ ${ }^{1 *}$ School of Nursing, Alex Ekwueme Federal University Teaching Hospital, Abakaliki \\ Ebonyi State, Nigeria \\ ${ }^{2}$ Department of Nursing Sciences, National Open University of Nigeria, Abuja \\ ${ }^{3}$ Department of Community Medicine, Alex Ekwueme Federal University Teaching \\ Hospital, Abakaliki \\ ${ }^{4}$ National Malaria Elimination Program, Department of Public Health, Federal Ministry \\ of Health, Abuja \\ *Corresponding author: Azuogu Victoria, School of Nursing, Alex Ekwueme Federal \\ University Teaching Hospital, Abakaliki Ebonyi State, Nigeria. \\ E-mail: azuoguvc@gmail.com, Phone number:+2347033791119
}

\begin{abstract}
Background: Pregnant women, children and immune-compromised persons are highly vulnerable to malaria morbidity and mortality. Malaria accounts for about 50\% of all clinic attendance in Nigeria and contributes significantly to anaemia in pregnancy, low birth weight, preterm births, still births and perinatal mortality. It is therefore imperative that these highly susceptible groups of people are adequately informed and supported for prevention of malaria at all times. This study assessed the knowledge and practice of malaria control measures among Antenatal Care attendees in Abakaliki.
\end{abstract}

Methods: A descriptive cross-sectional study was conducted in the two biggest hospitals in Abakiliki, among 400 Antenatal Care attendees selected using systematic sampling technique. Data was collected using interviewer administered questionnaire and analyzed using Statistical Package for Social Sciences version 22. Chi-square was used to test for associations between independent and dependent variables. The significance level was set at $p<0.05$.

Results: The mean age of respondents was $29.2 \pm 4.1$ years. Majority correctly identified methods of diagnosis of malaria in pregnancy. Although 375(93.7\%) of the women constantly owned a long-lasting insecticide treated net, only 187(49.9\%) of them always slept under it. While 363(90.7\%) of the respondents cleared their surrounding bushes, only 130 (32.5) regularly used in-door insecticide spray and 153(38.3\%) always used anti-malaria prophylaxis in the index pregnancy.

Conclusion: Knowledge about malarial control measures was high but use of Long-Lasting Insecticide Treated Net with drug prophylaxis was suboptimal. It is therefore recommended that health education on malaria prevention practice be intensified during Antenatal clinic visits.

Keywords: Knowledge; practice; malaria control measures; ANC attendees; Abakaliki 


\section{Introduction}

Malaria is a preventable systemic protozoan infection. It accounts for $1.5-$ 2.7 million deaths globally per annum and exerts enormous socio-economic burden in many developing countries. ${ }^{1}$ In 2018 , about 228 million cases of malaria and 405,000 deaths from the disease occurred worldwide, and the total funding by governments of malaria endemic countries and international partners was US\$ 2.7 billion for its control and elimination efforts. ${ }^{2}$ Most malaria cases (213 million or 93\%) and deaths (94\%) in 2018 occurred in the World Health Organization (WHO) African Region. ${ }^{2}$

Malaria infection during pregnancy (MIP) is a significant public health problem, with substantial risks for the pregnant woman, her fetus and the newborn child. Pregnant women are three times more likely to develop severe malaria disease than nonpregnant women acquiring infections from the same area. While the mechanism is poorly understood, pregnant women have a reduced immune response and therefore less effectively clear malaria infections. In addition, malaria parasites sequester and replicate in the placenta. ${ }^{3}$ Maternal anaemia, a consequence of MIP, puts the mother at increased risk of miscarriage, death before and after childbirth and leads to preterm births and children of low weight at birth, causing problems with child growth and cognitive development, as well as being major risk factors for perinatal, neonatal and infant mortality. ${ }^{1,3}$

To avert the consequences of malaria infections to pregnant women, fetuses, infants and children, WHO recommends the use of Intermittent Preventive Treatment in pregnancy (IPTp) with sulfadoxine-pyrimethamine (SP), in combination with vector control and prompt diagnosis and effective treatment of malaria, as part of antenatal care (ANC) in areas of moderate to high transmission in sub-Saharan Africa. ${ }^{2}$ By 2018, about $30 \%$ of pregnant women received three doses of IPTp ${ }^{2}$ compared with $13 \%$ of pregnant women who received at least two doses of SP during antenatal consultations in 2010 and 5\% who did so in $2008 .^{1}$ The WHO in 2012 reported that between 2008 and $2010,31 \%$ of children under-five years and $36 \%$ of pregnant women in rural areas nationwide used Long Lasting Insecticide Treated Net (LLIN) the night before the survey, representing a six and nine fold increase respectively.

In Nigeria, the ecological conditions, poor socio-economic factors and lack of access to effective preventive and curative health care delivery services compound malaria burden. The disease is transmitted throughout the country, with $76 \%$ of the population living in high transmission areas. ${ }^{5}$ In 2018, Nigeria accounted for $25 \%$ of the global malaria cases and $24 \%$ of global deaths from the disease. ${ }^{2}$ The National Malaria Strategic Plan (NMSP 2014-2020) targets for MIP include that at least $80 \%$ of pregnant women would sleep inside Insecticide Treated Nets (ITNs) by 2020, all eligible pregnant women attending ANC received at least three doses of SP-IPTp by 2020 and that by $2017,80 \%$ of pregnant women with fever and malaria received appropriate and timely treatment according to the national treatment guidelines, and 100 percent received appropriate and timely treatment according to the national treatment guidelines by $2020 .{ }^{5}$ Success in the control of malaria in the country is dependent in part on the knowledge and practices of the populations in the affected areas and on the past and present national policies on the treatment and control of malaria. ${ }^{6}$ This study therefore assessed the knowledge and practice of malaria control measures 
among ANC attendees in the two biggest hospitals in Abakaliki, Nigeria.

\section{Methods}

A descriptive cross-sectional study was conducted among antenatal care attendees in Abakaliki between October and November 2019. The minimum sample size was determined using the formula for single proportion ${ }^{7}$ to get 384 but roundedup to 400 , and selection was by systematic sampling technique using serially numbered cardboard papers given to the women by the nurses on their arrival at the clinics. The ANC clinics are run on Mondays to Fridays with over 90 women in attendance each day. Using sampling interval of three (based on the average daily clinic attendance of 90 and estimated 30 respondents per day) with the starting point determined by balloting between one and three, about thirty participants were selected each day over a four-week period. Those that did not give consent were replaced by the next available person without altering the original sampling interval flow. Only those that had had at least one previous ANC attendance were sampled.

Data was collected using a pre tested, semi-structured interviewer administered questionnaire. Good knowledge of control measures was assessed by the proportion of respondents who correctly answered $50 \%$ of the knowledge questions. Practice was assessed by the proportion of respondents who answered correctly the questions on practice. Statistical Package for Social Sciences (SPSS) version 22 was used for analysis. Chi-squared was used to test for associations between independent (age, marital status, level of education and occupation) and dependent (ownership of LLIN, sleeping under LLIN, clearing bushes and stagnant water, and use of indoor insecticide spray) variables with significance level set at $p<0.05$. Ethical approval was obtained from the Research and Ethics Committee (reference No. FETHA/REC/Vol.1/2014/205) of the Federal University Teaching Hospital Abakaliki (FETHA), Ebonyi State, Nigeria. Informed consent was obtained from the ANC attendees after full explanation of the study to them. Only those who gave their consent by signing the informed consent form participated in the study.

\section{Results}

A total of 414 women were approached but 400 gave consent and were interviewed, giving a response rate of $96.6 \%$. The mean age of respondents was $29.2 \pm 4.1$ years with majority; 320(80.1\%) being within 25-34 years age group. A large proportion of them; $160(40.0 \%)$ attained tertiary education, and they were predominantly; $178(44.5 \%)$ civil servants. Table 1.

In Table 2, large proportions; 359(89.7\%) and $283(70.7 \%)$ of the respondents correctly identified that MIP can be diagnosed by either testing for malaria parasite in the laboratory or by use of rapid diagnostic test respectively. Also $241(60.3 \%)$ of the respondents agreed that MIP can be diagnosed by the symptoms felt by the patients. However, a large proportion of respondents; 362(90.5\%) erroneously thought that regular attendance of ANC alone is adequate to prevent MIP rather than administration of SP and practice of IPT. Only $71(17.8 \%)$ of the respondents knew that only ACT is currently recommended for the treatment of malaria in pregnancy rather than chloroquine or herbal medicine.

Table 3 shows that almost all the respondents knew that malaria can be controlled by sleeping regularly under insecticide treated nets; 389(97.2\%), clearing of surrounding bushes; 383(95.7\%) and emptying stagnant water 
in containers and drainages; 382(95.5\%). In Table 4, most of the respondent; $375(93.7 \%)$ always owned a long-lasting insecticide net but only about half; $187(49.9 \%)$ of them always sleep under it Majority; 363(90.7\%) of the respondents cleared their surrounding bushes, while only $130(32.5 \%)$ always used in-door insecticide spray, and few $78(19.5 \%)$ always used anti-malaria prophylaxis prescribed in the index pregnancy.

In Table 5, ownership of LLIN was highest; $306(82.7 \%)$ in the $25-34$ years age-group but fewer of them; $147(48.7 \%)$ always slept under the nets, while out of the $26(7.0 \%)$ of those that owned LLIN in the 15-24 years age-group greater proportion, 21(80.8\%) always slept under the nets. These differences were statistically significant $(\mathrm{P} \leq 0.001$ and $\mathrm{p}=$
0.001 respectively). Most; 356(96.2\%) of the married respondents owned LLIN and about half; $181(50.8 \%)$ slept under them. More, $10(62.5 \%)$ of those that slept under their LLIN had primary education compared to those with tertiary level, a difference that was statistically significant $(P=\leq 0.001)$. In Table 6, there was statistically significant association $(\mathrm{P} \leq$ $0.001)$ between marital status and clearing of bushes/stagnant water with majority of the married participants; $341(95.3 \%)$ always clearing bushes/stagnant water compared to their single and separated counterparts. There was also a statistically significant association between occupation and use of in-door insecticide as it was predominantly the civil servants; $68(52.3 \%)$ and teachers; $29(22.3 \%)$ who practiced indoor insecticide spraying $(\mathrm{p} \leq 0.001)$. 
Table 1: Socio-demographic characteristics of the respondents

\begin{tabular}{|c|c|c|}
\hline Variables & Freq. $(n=400)$ & Percentage \\
\hline \multicolumn{3}{|l|}{ Age group (in years) } \\
\hline $15-24$ & 35 & 8.8 \\
\hline $25-34$ & 320 & 80.0 \\
\hline $35-44$ & 45 & 11.2 \\
\hline \multicolumn{3}{|l|}{ Marital status } \\
\hline Married & 373 & 93.3 \\
\hline Divorced or widowed & 14 & 3.5 \\
\hline Single & 13 & 3.2 \\
\hline \multicolumn{3}{|l|}{ Religion } \\
\hline Christianity & 329 & 82.3 \\
\hline Islam & 71 & 17.7 \\
\hline \multicolumn{3}{|l|}{ Ethnicity } \\
\hline Igbo & 253 & 63.2 \\
\hline Hausa & 95 & 23.8 \\
\hline Yoruba & 52 & 13.0 \\
\hline \multicolumn{3}{|l|}{ Educational status } \\
\hline Tertiary & 160 & 40.0 \\
\hline Post-secondary & 120 & 30.0 \\
\hline Secondary & 97 & $24 . .3$ \\
\hline Primary or below & 23 & 5.7 \\
\hline \multicolumn{3}{|l|}{ Husband's level of education } \\
\hline Tertiary & 260 & 65.0 \\
\hline Post-secondary & 100 & 25.0 \\
\hline Secondary & 33 & 8.2 \\
\hline Primary or below & 7 & 1.8 \\
\hline \multicolumn{3}{|l|}{ Occupation of respondent } \\
\hline Civil servant & 178 & 44.5 \\
\hline Trader & 129 & 32.3 \\
\hline Teacher & 59 & 14.7 \\
\hline Other (Farmer and Artisan) & 34 & 8.5 \\
\hline
\end{tabular}


Table 2: Knowledge about diagnosis, prevention and treatment of malaria in pregnancy

\begin{tabular}{llcc}
\hline Variable & $\begin{array}{l}\text { Yes } \\
\text { Freq (\%) }\end{array}$ & $\begin{array}{l}\text { No } \\
\text { Freq (\%) }\end{array}$ & $\begin{array}{l}\text { Don't Know } \\
\text { Freq (\%) }\end{array}$ \\
\hline $\begin{array}{llc}\text { Malaria in pregnancy is diagnosed by: } \\
\quad \text { Testing for malaria parasite (MP) in the lab }\end{array}$ & $359(89.7)$ & $10(2.5)$ & $31(7.8)$ \\
$\quad$ Rapid diagnostic test (RDT) & $283(70.7)$ & $14(3.5)$ & $103(25.8)$ \\
$\quad$ Symptoms felt by the pregnant woman & $241(60.3)$ & $25(6.2)$ & $134(33.5)$ \\
& & & \\
Malaria in Pregnancy can be prevented by: & & & \\
$\quad$ Regular attendance of ANC only & $362(90.5)$ & $9(2.3)$ & $29(7.2)$ \\
$\quad$ Administration SP drugs during pregnancy & $337(84.3)$ & $8(2.0)$ & $55(13.7)$ \\
$\quad$ Intermittent presumptive treatment (IPT) & $78(19.5)$ & $42(10.5)$ & $280(70.0)$ \\
& & & \\
Malaria in pregnancy can be treated by: & & & \\
$\quad$ Use of chloroquine & $83(20.8)$ & $37(9.2)$ & $280(70.0)$ \\
$\quad$ Use of ACT (Artemisin Combination Therapy) & $71(17.8)$ & $72(18.0)$ & $257(64.2)$ \\
Use of traditional/Herbal Medicine & $62(15.5)$ & $193(48.3)$ & $145(36.2)$ \\
\hline
\end{tabular}

Table 3: Knowledge about control of the vector that transmits malaria among the respondents

\begin{tabular}{lll}
\hline Variable & Yes & No \\
& Freq (\%) & Freq (\%) \\
\hline Vector that transmits malaria can be controlled by: & & \\
Sleeping regularly under insecticide treated net & $389(97.2)$ & $11(2.8)$ \\
Clearing bushes in our surroundings & $383(95.7)$ & $17(4.3)$ \\
Emptying stagnant water in containers and drainages & $382(95.5)$ & $18(4.5)$ \\
Putting door and window nets in our houses & $380(95.0)$ & $20(5.0)$ \\
Use of in-door insecticide spray/repellants to kill the vector & $378(94.5)$ & $22(5.5)$
\end{tabular}

Table 4: Practice of malaria control measures among respondents

\begin{tabular}{|c|c|c|c|}
\hline Variables & $\begin{array}{l}\text { Always } \\
\text { Freq (\%) }\end{array}$ & $\begin{array}{l}\text { Sometimes } \\
\text { Freq (\%) }\end{array}$ & $\begin{array}{l}\text { Rarely } \\
\text { Freq (\%) }\end{array}$ \\
\hline $\begin{array}{l}\text { Ownership of Long } \text {-Lasting Insecticide Net } \\
\text { (LLIN) }\end{array}$ & $375(93.7)$ & $0(0.0 \%)$ & $25(6.3)$ \\
\hline Sleeping under LLIN during pregnancy $(\mathrm{n}=375)$ & $187(49.9)$ & $181(48.3)$ & $7(1.8)$ \\
\hline Clearing bushes in the surroundings & $363(90.7)$ & $29(7.3)$ & $8(2.0)$ \\
\hline Emptying stagnant water in the surroundings & $360(90.0)$ & $32(8.0)$ & $8(2.0)$ \\
\hline Use of in-door insecticide spray & $130(32.5)$ & $239(59.8)$ & $31(7.7)$ \\
\hline $\begin{array}{l}\text { Used anti -malaria prophylaxis } \\
\text { prescribed in this pregnancy: }\end{array}$ & 78 (19.5) & $153(38.3)$ & $169(42.2)$ \\
\hline
\end{tabular}


Table 5: Association of socio-demographic characteristics with ownership and use of long-lasting insecticide nets among the respondents

\begin{tabular}{|c|c|c|c|c|c|c|}
\hline \multirow[t]{2}{*}{ Variables } & \multicolumn{3}{|c|}{ Ownership of LLIN } & \multicolumn{3}{|c|}{ Always sleep under LLIN } \\
\hline & $\begin{array}{c}\text { Yes } \\
\text { Freq }(\%)\end{array}$ & $\begin{array}{c}\text { No } \\
\text { Freq (\%) }\end{array}$ & $\begin{array}{c}\chi^{2} \\
\text { P-value }\end{array}$ & $\begin{array}{c}\text { Yes } \\
\text { Freq }(\%)\end{array}$ & $\begin{array}{c}\text { No } \\
\text { Freq }(\%) \\
\end{array}$ & $\begin{array}{c}\chi^{2} \\
\text { P-value }\end{array}$ \\
\hline \multicolumn{7}{|l|}{ Age group } \\
\hline $15-24$ & $26(7.0)$ & $9(30.0)$ & & $21(80.8)$ & $5(19.2)$ & \\
\hline $25-34$ & $306(82.7)$ & $14(46.7)$ & $2.451(\leq \mathbf{0 . 0 0 1})$ & $147(48.0)$ & $159(52.0)$ & $12.854(\mathbf{0 . 0 0 1})$ \\
\hline $35-44$ & $38(10.3)$ & $7(23.3)$ & & $14(36.8)$ & $24(63.2)$ & \\
\hline \multicolumn{7}{|l|}{ Marital status } \\
\hline Single & $5(1.4)$ & $8(26.7)$ & & $2(40.0)$ & $3(60.0)$ & \\
\hline Married & $356(96.2)$ & $17(56.7)$ & $21.752(\leq \mathbf{0 . 0 0} 1)$ & $181(50.8)$ & $175(49.2)$ & $0.369(\leq \mathbf{0 . 0 0 1})$ \\
\hline Separated & $9(2.4)$ & $5(16.6)$ & & $4(44.4)$ & $5(55.6)$ & \\
\hline \multicolumn{7}{|l|}{ Level of education } \\
\hline Tertiary & $148(40.4)$ & \multicolumn{2}{|l|}{$12(35.3)$} & $56(37.8)$ & \multicolumn{2}{|l|}{$92(62.2)$} \\
\hline Post -secondary & $112(30.6)$ & \multicolumn{2}{|l|}{$8(23.5)$} & $69(61.6)$ & \multicolumn{2}{|l|}{$43(38.4)$} \\
\hline Secondary. & $90(24.6)$ & $7(20.6)$ & \multirow[t]{2}{*}{$15.158(\mathbf{0 . 0 0 1})$} & $50(55.6)$ & \multirow{2}{*}{\multicolumn{2}{|c|}{ 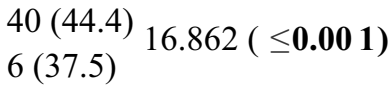 }} \\
\hline Primary or below & $16(4.4)$ & $7(20.6)$ & & $10(62.5)$ & & \\
\hline \multicolumn{7}{|l|}{ Occupation } \\
\hline Civil servant & $162(45.4)$ & $16(37.2)$ & & $66(40.7)$ & $96(59.3)$ & \\
\hline Teacher & $48(13.4)$ & $11(25.6)$ & $9.752(\mathbf{0 . 0 2 1})$ & $30(62.5)$ & $18(37.5)$ & $12.682(\mathbf{0 . 0 0 5})$ \\
\hline Trader & $120(33.6)$ & $9(20.9)$ & & $70(58.3)$ & $50(41.7)$ & \\
\hline $\begin{array}{l}\text { Others (Farmer or } \\
\text { Artisan) }\end{array}$ & $27(7.6)$ & $7(16.3)$ & & $16(59.3)$ & $50(41.7)$ & \\
\hline
\end{tabular}

Table 6: Association of socio-demographic characteristics with practice of malaria control measures among the respondents

\begin{tabular}{|c|c|c|c|c|c|c|}
\hline \multirow[t]{2}{*}{ Variables } & \multicolumn{3}{|c|}{ Always clear bushes and stagnant water } & \multicolumn{3}{|c|}{ Use in-door insecticide spray } \\
\hline & $\begin{array}{c}\text { Yes } \\
\text { Freq }(\%)\end{array}$ & $\begin{array}{c}\text { No } \\
\text { Freq }(\%)\end{array}$ & $\chi^{2}$ (P-value) & $\begin{array}{c}\text { Yes } \\
\text { Freq (\%) }\end{array}$ & $\begin{array}{c}\text { No } \\
\text { Freq (\%) }\end{array}$ & $\chi^{2}$ (P-value) \\
\hline \multicolumn{7}{|l|}{ Age group } \\
\hline $15-24$ & $30(8.4)$ & $5(11.4)$ & & $11(8.5)$ & $24(8.9)$ & \\
\hline $25-34$ & $291(81.8)$ & $29(65.9)$ & & $100(76.9)$ & $220(81.5)$ & \\
\hline $35-44$ & $35(9.8)$ & $10(22.7)$ & $7.402(\mathbf{0 . 0 2 5})$ & $19(14.6)$ & $26(9.6)$ & $2.185(\mathbf{0 . 3 3 5})$ \\
\hline \multicolumn{7}{|l|}{ Marital status } \\
\hline Single & $8(2.2)$ & $5(11.9)$ & & $7(5.1)$ & $6(2.3)$ & \\
\hline Married & $341(95.3)$ & $32(76.2)$ & & $124(91.2)$ & $249(94.3)$ & \\
\hline Separated & $9(2.5)$ & $5(11.9)$ & $75.439(\leq \mathbf{0 . 0 0 1})$ & $5(3.7)$ & $9(3.4)$ & $1.649(\mathbf{0 . 6 4 8})$ \\
\hline \multicolumn{7}{|l|}{ Level of education } \\
\hline Tertiary & $148(40.9)$ & $12(31.6)$ & & $62(46.3)$ & $98(36.8)$ & \\
\hline Post-secondary & $108(29.8)$ & $12(31.6)$ & & $43(32.1)$ & $77(29.0)$ & \\
\hline Secondary & $88(24.3)$ & $9(23.7)$ & & $22(16.4)$ & $75(28.2)$ & \\
\hline Primary or below & $18(5.0)$ & $5(13.1)$ & $4.792(\mathbf{0 . 1 8 8})$ & $7(5.2)$ & $16(6.0)$ & 7.467 (0.058) \\
\hline \multicolumn{7}{|l|}{ Occupation } \\
\hline Civil servant & $154(44.6)$ & 24 (43.6) & & $68(52.3)$ & $110(40.7)$ & \\
\hline Teacher & $50(14.5)$ & $9(16.4)$ & & $29(22.3)$ & $30(11.1)$ & \\
\hline Trader & $116(33.6)$ & $13(23.6)$ & $6.229(\mathbf{0 . 1 0 1})$ & $26(20.0)$ & $103(38.2)$ & $21.257(\leq \mathbf{0 . 0 0 1})$ \\
\hline $\begin{array}{l}\text { Others (Farmer or } \\
\text { Artisan) }\end{array}$ & $25(7.3)$ & $9(16.4)$ & & $7(5.4)$ & $27(10.0)$ & \\
\hline
\end{tabular}




\section{Discussion}

The mean age found in this study is similar to the mean age of respondents reported in previous similar studies in Ibadan. ${ }^{8-10}$ This is expected in view of the fact that pregnancy and attendance at antenatal care occur among women of reproductive age (15-45 years). A significantly large proportion of respondents had good knowledge about mosquito bite as means of malaria transmission in this study. This is in agreement with the figure obtained among residents in southern Ethiopia ${ }^{11}$ but at variance with that found in northern Ethiopia. ${ }^{12}$ The lower value obtained in this study despite the time lag compared with that of southern Ethiopia could be due to a possible difference in knowledge between mixed residents and a cohort of pregnant women.

A large proportion of respondents had good knowledge about correct diagnostic procedure for malaria in this study as it relates to laboratory testing for malaria parasite (MP) which is the gold standard despite the fact that rapid diagnostic test (RDT) has gained popularity due to the relative ease of performance and availability of result in few minutes. However, it is surprising that more than half of the respondents still believed that malaria is diagnosed only with the symptoms felt by the pregnant women. Their erroneous belief could be influenced by the earlier practice of using symptomatic diagnosis of malaria due to the challenges associated with laboratory testing for MP before the advent of RDT. This change in guideline should be emphasized in health education messages during ANC. Also, a significantly large proportion of respondents erroneously thought that regular ANC attendance alone was adequate to prevent MIP. Only a small proportion of the respondents knew that only ACT is currently recommended for the treatment of malaria in pregnancy rather than chloroquine or herbal medicine, and that IPT is the current strategy for prevention of malaria during pregnancy. The knowledge about IPT was far below the knowledge levels reported 7 years ago in Uyo. ${ }^{13}$ This large difference could be due to different methods of facility-based health worker and client physical interactions during ANC visits in those locations. The knowledge about use of ACT for treatment of MIP in this study was very poor considering massive awareness campaigns on radio stations in this region recently. However, this underscores the need for intensified targeted interactive physical awareness campaigns and health education that would permit question and answer periods rather than the one-way radio communications.

Knowledge about vector control measures against malaria was generally good among respondents in this study but this did not translate into corresponding good practice. For instance, a large proportion of respondents knew that sleeping under LLIN is effective in the prevention of malaria but only half of respondents who owned the nets always slept under it. Similarly, knowledge of ITN was also good but its ownership and usage during pregnancy were poor among pregnant women in a study done in Abuja. ${ }^{14}$ However in Ibadan, knowledge of ITN and possession of it were very good ${ }^{10}$ and its use in prevention of malaria was also relatively good. The proportion that always slept under LLIN in this study was an improvement over what was earlier found in Abeokuta ${ }^{15}$ and Uyo. ${ }^{13}$ It is equally above the WHO 2010 national value ${ }^{1}$ and those from Ibadan ${ }^{8}$ and Lagos $^{16}$ but lower than that found in Enugu. ${ }^{17}$ The progressive increase over the years is a reflection of positive effect of increased awareness 
programs. Also, the variation in knowledge and use of ITN among these respondents could reflect regional discrepancies in the frequency and effectiveness of awareness campaigns and this calls for review of campaign strategies in every part of the country. Efforts should be made to sustain the trend through intensified information and communication and distribution of insecticide treated nets.

A large proportion of respondents knew about the use of indoor insecticide spray in malaria prevention but only three-quarters of the respondents always used it. Also, a large proportion of respondents adopted clearing of surrounding bushes and emptying stagnant water in containers and drainages as strategies for malaria control and prevention. These findings are important for effective malaria control measures. Ownership of, and always sleeping under ITN/LLIN were significantly associated with age, while usage was more in the younger age group (15-24 years). Level of education had direct association with ownership of LLIN but always sleeping under the net took an inverse relationship except for those with post-secondary education. In a previous study, a significant relationship was reported between women's knowledge and their practice of malaria prevention. ${ }^{18}$ The lower level of sleeping under the LLINs among the highly educated women may also be connected with higher practices of bush and stagnant water clearing and use of in-door insecticide (found in this study). This kills the mosquitoes and makes the use of LLIN appear unnecessary. It could therefore be implied that environmental cleanliness and use of insecticide would reduce the need for sleeping under bed nets. This study also showed statistically significant association between ownership and always sleeping under LLIN by civil servants and traders. Ownership of LLIN and always sleeping under it increased significantly with increasing number of pregnancies in this study. This could result from ability to retain nets distributed previously and acclimatization to some discomforts associated with the nets, or an expression of beneficial effects of the nets from experience. Sleeping under LLIN declined slightly with increasing gestational age (GA) at booking for the index pregnancy. This could be influenced by reinforcement of health talks during subsequent ANC visits.

\section{Conclusion}

Knowledge about malarial control measures was high among the respondents. Practice on the environmental components of malarial control measures was also good. However, use of LLIN and IPT by the respondents as preventive measures was suboptimal. It is therefore imperative for intensified health education and awareness creation during ANC visits.

\section{References}

1. World Health Organization. Malaria in pregnancy; guidelines for measuring key monitoring and evaluation indicators. WHO Geneva 2010 . Available from: https://apps.who.int/iris/handle/1066 $5 / 43700$ ? show $=$ full. Accessed $10^{\text {th }}$ July, 2018

2. World Health Organization. World Malaria Report 2019. Available from: https://www.who.int/news room/feature-stories/detail/worldmalaria-report-2019. Accessed $20^{\text {th }}$ January, 2020.

3. Centers for Disease Control and Prevention. Treatment of Malaria (Guidelines For Clinicians), 2018. A va i a b l e from : https://www.cdc.gov/malaria/resourc 
es/pdf/clinicalguidance.pdf. Accessed $16^{\text {th }}$ January, 2020.

4. World Health Organization. Progress and impact of malaria control in Nigeria at a glance. WHO 2012 A v a i $1 \mathrm{able}$ e $\mathrm{rom}$ : http://www.rbm.who.int/ProgressImpact

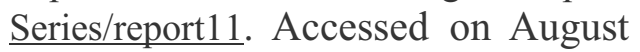
11,2018

5. USAID. President's Malaria Initiative Nigeira: Malaria Operational Plan FY 2019 . Available from: https://www.pmi.gov/docs/defaultsource/default-documentlibrary/malaria-operationalplans/fy19/fy-2019-nigeria-malariaoperational-plan.pdf? sfvrsn=3. Accessed $16^{\text {th }}$ January, 2020.

6. Federal Ministry of Health. National Malaria and vector control division National guideline for diagnosis and treatment of malaria for March 2011; 2: 14-16.

7. Araoye MO. Research methodology with statistics for Health and social sciences, Ilorin: Nathader Publisher; 2003:54-58.

8. Oladokun A, Oladoku RE, Adesina S. Knowledge and Utilization of malaria control measures by pregnant and newly delivered mothers in Ibadan, Nigeria. African Health Science; 2011; 11(4): 573-577.

9. Oladimeji KE, Tsoka-Gwegweni JM, Ojewole E, Yunga ST. Knowledge of malaria prevention among pregnant women and non-pregnant mothers of children aged under 5 years in Ibadan, South West Nigeria. Malar J. 2019;18(1):1-12.

10. Musibau AT, Evangeline AO, Oyedunni SA. Malaria prevention practices among pregnant women resident in two Nigeria army barracks, Ibadan, South Western, Nigeria. J Public Heal Epidemiol. 2017;9(4):92-8.
11. Ayalew S. Knowledge and Practice of malaria prevention methods among residents of Arba Minch town Ethiopia. Ethiopian Journal of Health Sciences. 2010; 20 (3):185-193.

12. Belay M and Deressa W. Use of insecticide treated nets by pregnant women and associated factors in predominantly rural population in northern Ethiopia. Ethiopian Journal of Health Sciences. 2008; 20 (3) 196204

13. Abasiattai A, Etukumana E and Umoiyoho A. Awareness and practice of malaria prevention strategies among pregnant women in Uyo south, Nigeria. The Internet Journals of Gynecology and Obstetrics. 2008; 11(1);23-29.

14. Akaba GO, Otubu JAM, Agida ET, Onafowokan O. Knowledge and utilization of malaria preventive measures among pregnant women at a tertiary hospital in Nigeria's Federal Capital Territory. Niger J Clin Pract. 2013;16(2):201-6.

15. Sam-Wobo SO, Akinboroye T, Anosike JC and Adewale B. Knowledge and practices on malaria treatment measures among pregnant women in Abeokuta, Nigeria. Tanzan J Health Res. 2008; 10(4): 226-31.

16. Efunshile M,Amoo AO, Akintunde GB and Ojelekan B. Use and effects of malaria control measures in pregnancy in Lagos, Nigeria. Korean J Parasitol 2011; 49(4):365-71.

17. Ugwu EO, Ezechukwu PC, Obi SN, Ugwu AO and Okeke TC. Utilization of insecticide treated nets among pregnant women in South Eastern Nigeria. Niger J Clin. Pract 2013; 10 (3): 293-6.

18. Ojong I, Iheanacho L, Akpan M and Nlumanze F. Knowledge and Practice of malaria prevention among 
pregnant women attending secondary health facility in Calabar, Cross River
State, Nigeria. Hamdard Med. 2013;56(3):70-7. 
